\title{
Lifetime follow-up care is necessary for all patients with treated thyroid nodules
}

\author{
M Dietlein and H Schicha \\ Department of Nuclear Medicine, University of Cologne, D-50924 Cologne, Germany \\ (Correspondence should be addressed to M Dietlein; Email: markus.dietlein@uni-koeln.de)
}

Leading thyroidologists in the United States and in Europe have most frequently recommended radioiodine (RAI) therapy when elimination of a solitary toxic nodule is indicated $(1,2)$. Interdisciplinary guidelines in Germany, authorized by the national associations of nuclear medicine, endocrinology and surgery, also give RAI administration as the therapy of choice for this indication (3). How then can the contradictory results of the cost-effectiveness analysis of Vidal-Trécan et al. in France (4) be explained? This analysis shows RAI administration to be an effective therapy only in the oldest of patients.

In their 'Methods' chapter the authors Vidal-Trécan et al. (4) explain their methods of estimation and decision trees, indicating the crucial factors on which their analysis is based.

\section{Use of resources}

In the cost-effectiveness analysis of Vidal-Trécan et al. (4), surgically treated patients were followed for only 1 year, whereas after RAI therapy patients had lifetime follow-up care. Annual measurement of thyrotrophin (TSH) levels is indeed necessary after RAI therapy, but it is also standard practice in Germany for surgically treated patients to receive medication (levothyroxine, iodine or a combination) to compensate for iodine deficiency, to avoid elevated TSH stimulation and to prevent a recurrent goitre within the time period of four decades chosen for Vidal-Trécan's decision tree. Our own economic analysis in Germany has shown that the costs of lifetime follow-up care far exceed the cost of a single procedure (RAI therapy or lobectomy) (5). Full consideration of all cost factors is standard procedure in cost-effectiveness analyses $(6,7)$.

From the medical point of view, one advantage of RAI therapy is that the recurrence rate is relatively low and certainly lower than that in surgically treated patients without prophylactic medication.

The authors' assumption (4) that one to three courses of RAI administration are necessary for the elimination of a solitary hyperfunctioning nodule is unrealistic, given a dose concept of 300-400 Gy to the target volume and the discontinuation of antithyroid medication 2 or 3 days before RAI administration (3).
The authors conclude that the low-dose concept is more cost effective than the high-dose concept, whereas actually other factors are more crucial for minimizing the rate of hypothyroidism. In many guidelines $300-400 \mathrm{~Gy}$ to the autonomous tissue is given as the recommended dose for elimination of an autonomous nodule. The ratio of nodule volume to thyroid volume, the optimal suppression of the normal surrounding thyroid tissue and pretherapeutic testing of the iodine kinetics $\left({ }^{131}\right.$ I uptake, effective half life) are more critical factors for minimizing the rate of hypothyroidism.

The economic consequences of low-dose or high-dose concepts of RAI therapy of Graves' disease have already been discussed in Scotland, Sweden and Germany. These analyses have shown the high-dose concept to be the more cost-effective strategy $(5,8,9)$ because the subsequent levothyroxine substitution guarantees a stable euthyroidism without the risk of recurrent hyperthyroidism, while reducing the frequency of follow-ups needed.

\section{Effectiveness}

In the authors' decision tree (4) the rate of concurrent thyroid cancer detected during surgery and histopathological examination was reported to be 700:100 000. This high prevalence results from the high frequency of incidental papillary microcarcinomas (capsulated, well-differentiated carcinomas $\leq 1 \mathrm{~cm}$ in diameter). Such microcarcinomas are biologically silent, nonaggressive tumours. A valid estimation of a hypothetical mortality rate is difficult to find in the literature. This may be why the estimated mortality rates were taken from a review article (10) and not from an original paper. Vidal-Trécan et al. (4) calculated a mortality rate of $5.8 \%$ per year for an undetected thyroid cancer. But this mortality rate cannot be applied to the patients group with a high prevalence of occult papillary microcarcinomas. Furthermore, there is the problem that the estimated incidence and the estimated mortality rate are not taken from the same group of patients. Physicians and patients assume a malignancy rate of only 1:3000 per nodule in regions of endemic goitres. Estimations skewed by the high incidence of papillary 
microcarcinomas will cause unnecessary anxiety amongst patients. A sufficient risk stratification for malignant or benign nodules can be reached with a combination of sonography, scintigraphy and needlebiopsy. Moreover, the most differentiated thyroid cancers $>1 \mathrm{~cm}$ can be cured by multimodality therapy concepts (thyroidectomy, compartmental lymphadenectomy, RAI therapy, risk-adapted follow-up care). In summary, the mortality rate of concurrent thyroid cancers is overestimated in the decision model.

On the other hand, the mortality rate after a surgical procedure, as estimated from the model of Trécan-Vidal et al. (4), is very low $(0.001 \%)$ even in women over 80 years of age $(0.003 \%)$. Figures as good as this cannot be applied to an entire health care system.

The low frequency of hypothyroidism described after lobectomy (only 4\%) is not the main factor determining whether follow-up care should be recommended. Even when TSH is in the upper region of the reference range prophylactic medication will be necessary to prevent recurrent goitre and to minimize the risk of a second operation in the future. The clinical approach of the 1950s and 1960s, which omitted prophylactic medication, was detrimental to patients - many surgically treated patients had a further operation for recurrent goitres.

\section{Quality of life}

The authors assumed that continued monitoring for euthyroidism after RAI therapy would lower the patient's quality of life (4). In our opinion, such monitoring could be limited to an annual measurement of the TSH level, combined with other medical examinations. TSH controls are also necessary after surgery (see Use of resources).

Without any (prophylactic) medication or lifetime follow-up there will be a measurable rate of recurrences in the surgically treated group of patients within the given time scale of four decades. This would decrease the quality of life even more than an annual TSH control after RAI therapy.

Dysphonia after lobectomy has serious consequences for the given index patient, at 40 years of age, i.e. over the best years of his or her working life. But the estimated quality of life adjustment factor in the case of permanent dysphonia (0.98 instead of 1.0) is very similar to that of routine controls (0.99) or to that of levothyroxine medication in the case of hypothyroidism (0.99). We think the lowering of quality of life through paralysis of the vocal nerve is worse than the assumed reductions cited.

The lowering of quality of life in women of childbearing age in the sensitivity analysis is questionable. Contraception is necessary for $4-6$ months after RAI therapy. But there are no genetic risks and no restrictions for pregnancy after this initial 4-6 month period. Most females of 40 years (the index patient) have completed their family planning. Vidal-Trécan et al. stated that women should avoid pregnancy for one complete year following RAI administration. This period of contraception is too long. The authors' recommendation of lobectomy for women under 50 years due to poor compliance with regard to contraception is inappropriate today.

\section{Economic data from other countries}

A cost-minimization analysis in Germany compared surgery and RAI therapy for the treatment of hyperthyroidism in a mixed group of toxic nodular goitres and Graves' disease patients. Using the posttherapeutic dosimetry administered during hospitalization in Germany, RAI therapy was more cost effective than surgery in toxic nodular goitre of up to $90 \mathrm{ml}$ and in toxic solitary nodules of up to $25 \mathrm{ml}(11-13)$. The cost-minimization analysis is based on retrospectively matched groups. In our view it is ethically unjustified to discuss the necessity of a randomized trial including patients with toxic nodules and a well-established indication for RAI therapy.

\section{Safety of RAI therapy}

The model for estimation of the occurrence of thyroid cancer after RAI administration is based on the data of Franklyn et al. (14) and Ron et al. (15) published in 1998. Both long-term studies included historical groups in which laboratory tests, scintigraphy and sonography were not available. The incidence of suspect nodules or of co-existing carcinomas therefore remains unclear.

In the study of Franklyn et al. (14) the patients had received RAI therapy beween 1950 and 1989. Increased mortality was observed, especially in the first year after RAI therapy. One explanation is that the increased mortality might result from hyperthyroidism not compensated for by antithyroid drugs and from the consequence of selective sampling of critically ill patients. The time interval of one year is too short for the induction of cancer.

In the study of Ron et al. (15) RAI therapy had been performed between 1946 and 1964. The overall cancer mortality rate in the cohort after RAI therapy was not significantly increased $(1.02$, normal $=1.0)$, cancer mortality rates for uterus and prostate carcinomas were decreased (0.69 and 0.67), and the cancer mortality rate for thyroid cancer was increased (3.94). The elevated risk of thyroid cancer was observed in the first 5 years after RAI therapy, an interval too short for the induction of a new carcinoma. In the surgically treated group increased cancer mortality rates were found for lung and breast cancer (1.17) and decreased cancer mortality rates for uterus carcinoma 
(0.57) and myeloma (0.48). Following antithyroid drugs treatment, mortality rates were increased for cerebral tumours (3.7) and carcinomas of the oropharynx (4.2). Approximately 2000 correlations were made in the study of Ron et al. The positive correlations should be interpreted with caution. Statistically, with a significance level of $5 \%(P<0.05)$ and that number of correlations, about 100 randomized, false-positive correlations might be expected. Indeed, the study of Ron et al. had found 70 significant correlations. In summary, Ron et al. concluded: 'Overall, ${ }^{131} \mathrm{I}$ appears to be a safe therapy for hyperthyroidism' (15).

It is not improbable that the cancer risk in patients with nodular goitres or thyroid disorders is higher than in healthy individuals, because thyroid cancers are usually presented as nodular goitres. This correlation was shown in a multicentre cohort study from Denmark including 57326 probands. In the study of Mellemgaard et al. (16) the rate of thyroid cancer was increased in patients with myxoedema (2.1), hyperthyroidism (2.5) and euthyroid goitre (6.6) compared with healthy individuals (base rate of cancer incidence in the course of their lives $=1.0$ ). The guidelines in Germany, therefore, demand consistent use of sonography, scintigraphy and - if needed - fine-needle biopsy in each patient with a thyroid nodule $\geq 1 \mathrm{~cm}$.

Interpreting the data of Ron et al. (15), Cooper wrote in his editorial: 'Until then, given the known benefits, risks and costs, ${ }^{131}$ I will continue to be the treatment of choice for most hyperthyroid patients' (17).

\section{References}

1 Wartofsky L. Treatment options for hyperthyroidism. Hospital Practice $19963169-73,76-78,81-84$

2 Reiners C \& Schneider P. Radioiodine therapy and thyroid autonomy. European Journal of Nuclear Medicine and Molecular Imaging 200229 (Suppl 2) S471-S478.

3 Dietlein M, Dressler J, Joseph K, Leisner B, Moser E, Reiners C et al. Leitlinie zur Radioiodtherapie (RIT) bei benignen Schilddrüsenerkrankungen. Nuklearmedizin 199938 219-220.

4 Vidal-Trécan GM, Stahl JE \& Durand-Zaleski I. Managing toxic thyroid adenoma: a cost-effectiveness analysis. European Journal of Endocrinology 2002146 283-294.
5 Dietlein M, Moka D, Dederichs B, Hunsche E, Lauterbach KW \& Schicha H. Kosten-Effektivitäts-Analyse: Radioiod oder thyreostatische Medikation bei der Primärbehandlung der Immunhyperthyreose. Nuklearmedizin 199938 7-14.

6 Dietlein M, Knapp WH, Lauterbach KW \& Schicha H. Economic evaluation studies in nuclear medicine: the need for standardization. European Journal of Nuclear Medicine 199926 663-680.

7 Drummond MF \& Jefferson TD. Guidelines for authors and peer reviewers of economic submissions to the BMJ. British Medical Journal $1996313275-283$.

8 Hardisty CA, Jones SJ, Hedley AJ, Munro DS, Bewsher PD \& Weir RD. Clinical outcome and costs of care in radioiodine treatment of hyperthyroidism. London Journal of the Royal College of Physicians 199024 36-42.

9 Ljunggren JG, Törring O, Wallin G, Taube A, Tallstedt L, Hamberger B et al. Quality of life aspects and costs in treatment of Graves' hyperthyroidism with antithyroid drugs, surgery, or radioiodine: results from a prospective, randomized study. Thyroid $19988653-659$.

10 Tengs TO \& Wallace A. One thousand health-related quality-oflife estimates. Medical Care 200038 583-637.

11 Dietlein M, Geckle L, Overbeck T, Moka D, Bausch V, Troche C et al. Kostenminimierungsstudie zur definitiven Therapie der Hyperthyreose: Vergleich zwischen Strumaresektion und Radioiodtherapie. Nuklearmedizin 199736 150-156.

12 Dietlein M, Lauterbach KW \& Schicha H. Treatment of toxic nodular goitres: comparative costing of radioiodine therapy and surgery. Experimental and Clinical Endocrinolgy and Diabetes 1998 106 (Suppl 4) S66-S70.

13 Dietlein M, Troche CJ, Moka D, Bausch V, Lauterbach KW \& Schicha H. Auswirkungen der neuen Entlassungsrichtwerte auf die Kostenstruktur der Radioiodtherapie. Nuklearmedizin 1998 $3726-33$.

14 Franklyn JA, Maisonneuve P, Sheppard MC, Betteridge J \& Boyle P. Mortality after the treatment of hyperthyroidism with radioiodine. New England Journal of Medicine 1998338 712-718.

15 Ron E, Doody MM, Becker DV, Brill AB, Curtis RE, Goldman MB et al. Cancer mortality following treatment for adult hyperthyroidism. JAMA $1998 \mathbf{2 8 0} 347-355$.

16 Mellemgaard A, From G, Jorgensen T, Johansen C, Olsen JH \& Perrild $\mathrm{H}$. Cancer risk in individuals with benign thyroid disorders. Thyroid $1998 \mathbf{8} 751-754$.

17 Cooper DS. Radioiodine for hyperthyroidism, where do we stand after 50 years? JAMA $1998 \mathbf{2 8 0} 375-376$.

Received 29 October 2002

Accepted 13 December 2002 